\title{
All English Teaching Methods for Network and Distributed Computing Course of Software Engineering
}

\author{
Zhidong Shen* \\ School of Cyber Science and Engineering \\ Wuhan University \\ Wuhan 430079, China \\ Email: zhidongshen@163.com
}

\author{
Qiang Tong \\ Software College \\ Northeastern University \\ Shenyang 110169, China
}

\begin{abstract}
An important way of training international computer science and software engineering professionals is to adopt all English teaching mode so that students can adapt to the training mode of international professionals as soon as possible. The all English teaching mode of Chinese students is still in the early stage, and it is an urgent task to explore its methodology. According to Wuhan University software engineering undergraduate course network and distributed computing teaching practice. We introduce the calculation of teaching experience, ideas and methods of network and distributed computing course. Four aspects of the teaching process in the course is described and analyzed. We also presented the synthetic mode of all English teaching including four elements in the course. Considering the need of software engineering whole English teaching we put forward some suggestions on the teaching mode and curriculum construction, carry out all English teaching mode provides a refe rence for other courses.
\end{abstract}

Keywords-all English teaching; network and distributed computing; teaching methodology; curriculum building

\section{INTRODUCTION}

At present, as a primary subject, software engineering has been paid more and more attention by many colleges and universities. It has achieved good results in the field of discipline construction and talent training, which shows a good trend of development. With the great input of the state departments in the field of university education, many universities have obviously improved and optimized the teaching environment for the teaching of software engineering, which has laid a good foundation for the future of the teaching of software engineering in Colleges and universities. At present, the reform of undergraduate education and teaching in universities is in the stage of deep development. The teaching of software engineering courses should meet the requirements of the reform of undergraduate education. The teaching quality and teaching level must meet the requirements of the overall construction and development goals of the school [1]. In the new situation, we need to explore the teaching methods of software engineering courses, deepen the teaching reform, face the trend of international development, and promote the

This work is supported by Wuhan University's teaching reform project 2015 undergraduate all English course of Network and Distributed Computing * Corresponding author: zhidongshen@163.com construction of software engineering courses.

Wuhan University has formulated a series of training programs for the undergraduate students of software engineering in combination with the training needs of software engineering professionals and the training goals of internationalization. The network and distributed computing course, as the basic course of software engineering major, mainly introduces the basic knowledge and application technology of computing network and distributed computing to students. In recent years, I have been engaged in teaching and scientific research of software engineering, and have undertaken the whole English Teaching of network and distributed courses. In actual teaching, comparing with the similar basic courses, the actual teaching effect is quite different. Below, this paper will analyze and discuss from the four stages of teaching process.

\section{EARLY STAGE OF TEACHING}

The course of network and distributed computing is oriented to the three grade students of software engineering. The students have a strong interest in learning and knowledge of computer and software programming. At the same time, because of the wide application of Internet technology, students generally have high expectations for the professional knowledge and application technology of network and distributed computing that will be studied. However, because of the wide application of network technology and distributed computing technology, the related technology is rich and complex, which causes the students to be confused when they first enter the field. At the same time, because all English courses have considerable demands on English ability, these factors have increased the difficulty of teaching in this course objectively. In spite of this, from the requirements of undergraduate education and the training goal of Wuhan University, it is of great significance to combine the organization of the teaching of professional knowledge with the English teaching method. Therefore, from the perspective of teaching students in accordance with their aptitude, before teaching, it is necessary to communicate with students in advance. On the one hand, we can understand the students' situation. On the other hand, we can briefly introduce the basic content and teaching arrangements of the network and 
distributed computing courses to the students. And by introducing the position of the course in the whole software system, the students have a preliminary correct understanding of the knowledge, the learning goals and the practical tasks of the course. This is mainly to weaken learning difficulty and enhance learning confidence and motivation. Because the course is oriented to the three grade students, the students at this stage have begun to show different professional interests and gradually have a preliminary choice and plan for the future direction of professional development. This factor also needs attention in the teaching process of this course. For example, students who are interested in seeking development in the field of network and distributed systems can improve their learning depth in the application of Internet and distributed computing technology according to their interest in learning, and play a leading role in guiding their students to stimulate their interest and interest in learning. Motivation to promote and help other students. And some students will be interested in other branches of software engineering in the future, and have targeted guidance to this part of the students. By introducing the connections between network and distributed computing technology and other professional branches, they will promote their awareness of the relevance and systematic aspects of their professional knowledge so that they can make the network and The knowledge and technology of distributed computing combine with the professional direction of interest to form a good support. At the same time, in combination with all English teaching, it is necessary to guide students to deepen the learning of professional English. For example, the study and discussion of English literature can effectively improve the students' reading ability in the field of network and distributed computing, and lay a solid foundation for further study. From the actual teaching situation, in the early stage of teaching, the teaching methods and methods mentioned above have a positive effect on the teaching of this course, and achieve better teaching results, thus laying a good foundation for the followup teaching of the course.

\section{CURRICULUM MATERIALS AND TEACHING MATERIALS}

According to the training requirements of software engineering major and the teaching requirements of network and distributed computing courses, and considering the diversity and complexity of network technology, and the wide application and rapid development trend of the current Internet technology, this course focuses on the learning of Internet technology, so the selection of the side should be on the side. Textbook books on heavy Internet technology. At the same time, considering the use of distributed computing technology in Internet applications, the selection of textbooks and reference materials in this course will also include the content of distributed computing technology. At present, the published textbooks of network technology in China are mostly classified into basic knowledge, basic principles and basic application skills. After years of practical teaching, I believe that these textbooks are more suitable for non-software engineering majors. This kind of teaching material generally tells the basic knowledge very carefully, and has a great length of introduction about the practical application of network technology and network software, is conducive to the rapid introduction of students, and also in line with the requirements of the High Education Department of the Ministry of education on the teaching content of Computer Basic courses for non-computer majors ([2004]136 of the high education department). But for software engineering majors, it is not appropriate to choose such textbooks. At present, the textbooks of basic courses published in software engineering in China are still in the stage of continuous improvement. As a software engineering specialty, it is a required course for network and distributed computing. It aims to better combine the characteristics of software engineering to guide students to understand the basic knowledge and application technology of network and distributed computing technology, and to choose and apply in the process of software design and development. Using targeted network and distributed computing technology. For professional students, this course emphasizes a more comprehensive understanding of the structure and application of the network. It can effectively master the key technologies which are representative and understand the trend of the application of network distributed computing. Therefore, the teaching content is systematic, representative and forward-looking. Therefore, in the course of the course, we select the original English version of Computer Networking: A Top Down Approach[2], which is more commonly used by foreign universities and universities, and choose the Java Network Programming[3] as a supplement to the content of the distributed computing technology. The original English edition is concentrated on the content of computer network technology represented by the Internet. It is suitable for the student students of the software engineering major to understand the general network technology. On the other hand, the original English version of the textbook is clearer, more systematic and more systematic. With a large number of cases, students' learning enthusiasm can be improved. The teaching resources website, which is synchronized with the curriculum, provides a good program for teaching practice, which makes students gradually familiarity with network and distributed computing techniques and practical skills in the process of learning, thus consolidating the content of classroom teaching. Moreover, the design of the practical case is lively and interesting, and the discussion of the problems is representative and forward-looking, stimulating the students' interest in exploration and obviously enhancing the teaching effect of this course. In the course of the actual teaching, we also provide some English references to students, which focus on the research and discussion of some typical problems of network and distributed computing technology, which can effectively promote students' understanding of the key technical problems in this field, look forward to the development trend of the field, and improve the students' professional English reading ability.

According to the students' situation, the teaching of network and distributed computing course adopts two ways of bilingual teaching and all English teaching, and the 
original English textbooks are used to gradually implement the English Teaching in the course of professional courses so as to adapt to the development trend of international running. Through the actual teaching of this course, I think it has good practice basis and maneuverability to popularize all English Teaching in the course of undergraduate software engineering. For most key university students, English reading in this course is not a big problem, which is equivalent to the continuation of College English curriculum. Of course, there are also some difficulties, mainly in terms of professional vocabulary and professional description. Although some of the students may not be able to adapt to it at the beginning, after the gradual guidance, plus the teaching explanation in Chinese, the actual effect has reached the teaching expectation. Therefore, the teaching of network and distributed computing course adopts the original English textbook, the English lecture (PPT) and all English explanations, and the practice guidance of the computer is bilingual teaching. From the perspective of students' actual reflection, this version of English teaching material has played a great role in promoting its college English learning in the same period. The use of foreign language teaching materials can not only make students get in touch with the thought, theory and technology of the original foreign scholars, but also be familiar with their professional thinking mode, and help to cooperate with their English learning. It is helpful to consolidate and strengthen the vocabulary of English, and to master the common English language as soon as possible. The characteristics of software engineering specialty also decide that students in this major will learn to use English in a large extent in the future. It's very necessary to develop professional English quality gradually from their enrollment. At present, we have gradually transferred from the bilingual teaching model to the full English teaching model. The original English version is used basically. The English model is adopted for the students of the international class and the excellent class students. Both the experiment report and the course examination are all used in the English model, which effectively improves the students' professional application and expression ability, which has laid a good foundation for them to adapt to the internationalization trend of software engineering in the future.

\section{TEACHING CONTENT ARRANGEMENT}

In the actual teaching process, the network and distributed computing course is quite different from the original courses. In traditional computing network courses, the introduction of basic principles accounted for more than $80 \%$, but the application of the current network technology is less, and the prospect of network development is rarely discussed. In terms of basic knowledge, this paper mainly introduces some basic concepts, principles and basic techniques of computer network, such as the five-layer architecture of OSI [4], and are relatively small in the principle and application of the Internet technology. At the same time, less software technology related to the network is designed and the network program based on distributed computing is used. The key technical introduction of the design is rarely involved.

These conditions are not appropriate for the training of the professional knowledge and technology of the software engineering students. It is necessary to strengthen the introduction of the current mainstream network technology in the network course and the explanation of the key technology of the application based on the network distributed environment. The goal of this course is to make students master the basic principles and technical methods of network and distributed computing, and to systematically study the Internet oriented network architecture, working principle, network protocol, data communication, and the principle of network distributed computing and programming and so on, for the future master of Internet The application and development of network lay the foundation of theory and technology. The main contents include: computer network architecture and Internet network composition (4 hours); Internet network application layer protocol, TCP and UDP socket programming (8 hours); network transport layer protocol, TCP and UDP protocol, TCP working principle; network layer principle and related protocol, IP protocol (8 school hours); data link layer worker Principles and protocols, methods of network media access control (8 hours); working principles of distributed computing and distributed systems, distributed computing design and implementation methods (8 hours); course practice (18 hours). This content basically cover the basic content of current mainstream network and distributed computing technology, and reflect the combination of network application technology and software development technology, which can better adapt to the training requirements of software engineering students.

In addition to classroom teaching, network and distributed computing courses are also a very important link. For the students of software engineering, it is necessary to improve the practical ability. In the teaching of network and distributed computing course, by setting up rich matching exercises, it effectively improves the students' learning effect and consolidates the absorption of teaching content. After each section, there are corresponding Quiz exercises. These exercises mainly check students' basic knowledge, basic concepts and methods learned in the corresponding chapters. Each chapter is rich in Quiz practice, can be selected according to the situation, can be used with small test or students' own review test after class, so that the students' knowledge can be checked as soon as possible, and it also has the effect of reviewing and consolidating. Each chapter has a corresponding Exercise after class, and exercises the knowledge of each chapter. Teachers can learn students' learning situation in time according to the assignments submitted by students. In combination with the case of English original textbooks, we design Exercise cases, and try to combine the current technical development trend to make the case design rich and vivid, can improve the interest of students well, and promote the students to 
actively invest in the review and distillation of the course content.

\section{TEACHING METHODS}

The course of network and distributed computing is taught in all English original textbooks, and the classroom teaching is based on the combination of multimedia teaching in the classroom and the practice of the machine. The main content of the classroom teaching is consolidated and deepened through practice guidance and practice, so that students can understand the mainstream network technology more comprehensively. Distributed computing technology, and through the analysis of the principles and development process of key technologies, enables students to understand the fast developing Internet and distributed computing technology and application trends from a more professional perspective.

In the teaching practice of this course, we change from the traditional single mode of "teaching" into the "four elements" synthetic mode of all English teaching. Those four elements are Lecture, Practice and Project, group discussion and teacherstudent Interaction, and classroom Quizzes. And make full use of the students' learning psychological characteristics, actively mobilize their subjective initiative, and cultivate the practical ability and creative thinking (for example, the development of Internet innovation application). In the course of teaching, according to the state of students and the degree of acceptance at any time, the rhythm of teaching is controlled flexibly so as to achieve a good teaching effect to the greatest extent. The current teaching methods pay more attention to the practicality and Enlightenment of the teaching effect. After the students have finished the course, they should accumulate the practical technology and experience of the international Internet development through the group project design. From the current teaching practice, students have a strong interest in network and distributed computing technology. They can cooperate and play enthusiasm with the project team in the course practice, effectively and effectively exercise the technical ability of the network and distributed computing application design and development, and the ability to communicate and coordinate the project.

The author has nearly 10 years of bilingual teaching experience, which has laid a solid foundation for the smooth development of all English Teaching in this course. By carrying out the training mode of all English teaching, the students' comprehensive application ability of professional English is obviously improved, especially the ability of reading
English literature and the ability of English communication in the field of specialty. It can be more effective in tracking the latest developments in the field of international network technology. It is a good embodiment of all English Teaching in this course. The characteristics and advantages of the learning model.

\section{CONCLUSION}

As the teaching contents and methods used in the network and distributed computing course are suitable for the professional training of the undergraduate students of software engineering, good results have been achieved in the teaching practice of the software engineering of Wuhan University in recent years. In the light of the actual teaching situation, the author analyses the four aspects of the teaching of network and distributed computing course, and puts forward some suggestions for reference. In the future work, we will continue to carry out the teaching and research of network and distributed computing, and improve the contents and teaching methods of this course.

\section{ACKNOWLEDGMENT}

We are deeply grateful to our colleagues in the International School of Software of Wuhan University for their support and help in this project.

\section{REFERENCES}

[1] Wei Yinchun, Wen Junhao, Chen Shuyu. Taking capability training as the core, constructing the practice teaching system of exemplary software college[J]. CHINA HIGHER EDUCATION, 2011(2): 49-50. (In Chinese)

[2] James F. Kurose, Keith W. Ross. Computer Networking: A Top Down Approach, 6th edition[M]. Pearson,2012.

[3] Harold, Elliotte Rusty. Java Network Programming[M], O'Reilly Media,2013.

[4] Andrew S.Tanenbaum, David J.Wettherall. Computer Networks, Fifth Edition [M]. China Machine Press, 2011.

[5] Zhang Qianfan. On the all-English teaching mode in university[J]. Journal of High Education,2003(04):91-93. (In Chinese)

[6] Research group of software engineering discipline system of Ministry of Education. China Software Engineering Curricula[M]. Tsinghua Publishing House,2005. (In Chinese)

[7] He Yin, Yu Lu. Problems and Countermeasures of computer network course teaching in Colleges and Universities[J]. Telecom World,2015.10,pp279-280. (In Chinese) 